\title{
El concepto frontera en la geografía humana
}

\section{The frontier concept in human geography}

Juan Carlos Arriaga Rodríguez ${ }^{1}$

\section{Resumen}

En las ciencias sociales, el concepto frontera tiene diferentes significados y usos explicativos en lo temporal y lo espacial. En cada época histórica y lugar del planeta, el concepto y sus palabras equivalentes tienen funciones políticas, económicas, militares y sociales diferentes. El siguiente texto es un artículo de revisión en el que se explica que las diferentes definiciones del concepto frontera en la geografía humana fueron construidas a lo largo del siglo $\mathrm{XX}$ con base en determinadas categorías geográficas, fenómenos y procesos sociales, y en los sujetos involucrados en tales procesos. Se explican las dos posturas dominantes en torno al concepto frontera dentro de la geografía humana: la "frontera como espacio absoluto" y la "frontera como espacio socialmente construido". Se analizan las tesis elaboradas en el marco de esas posturas, y se mencionan aquellas que han tenido una influencia directa en el estudio de las fronteras en América Latina.

Palabras clave: Espacio absoluto, espacio social, frontera, geografía humana, límite, región estratégica, territorio.

\section{Abstract}

In the social sciences, the "frontier" concept has different meanings and explanatory uses for temporal and spatial issues. In every historical period and place, this concept and its equivalent words have had different political, economic, military and social functions. The following is a review article that explains that different definitions of frontier concept in the field of the Human Geography were built during the 20th century based on certain geographical categories, social phenomena and processes, and on the actors involved in such processes. The paper explains the two key positions around the concept "frontier" in Human Geography: "frontier as an absolute space" and

Doctor en Historia Moderna y Contemporánea por el Instituto de Investigaciones Históricas México. Filiación Institucional: Profesor en el Departamento de Estudios Políticos e Internacionales y en el Doctorado en Geografía, Universidad de Quintana Roo. Miembro del Cuerpo Académico de Estudios Estratégicos y de Frontera. País: México. Correo electrónico: arriaga@uqroo. mx; jcar95@gmail.com 
"frontier as a socially constructed space". It analyzes the thesis developed in the framework of these positions, and highlights those who have a direct influence on the geographical study of frontiers in Latin America.

Keywords: Absolute space, social space, frontier, human geography, limit, strategic región, territory. 


\section{Introducción}

En la historiografía y el derecho, a la frontera no se le identifica con alguna categoría geográfica específica, es simplemente espacio histórico o espacio territorial. Si bien en la geografía humana la identificación de las categorías geográficas es importante para explicar el origen y evolución de las fronteras, esto no lo es para la historiografía y el derecho, pues para ambas disciplinas es suficiente con definir la frontera por los elementos que contiene, y no por el lugar que representa en un ámbito geográfico mayor. En las concepciones histórica y jurídica, la frontera es un contenedor inerte de cosas: para la historiografía es el marco de acontecimientos sociales del pasado, para el derecho es el contenedor de normas jurídicas.

En la geografía humana existen diversas definiciones del concepto frontera, cada una construida a partir de la combinación de las categorías espaciales (zona, región, territorio), fenómenos y procesos sociales que ocurren en los espacios de frontera y los sujetos sociales involucrados en tales procesos. Las diferentes combinaciones de esos elementos producen significados distintos del concepto frontera.

No obstante, consideramos que es posible agrupar en dos posturas epistemológicas toda esa diversidad de definiciones del concepto frontera en la geografía humana. Estas posturas son: la frontera como "espacio absoluto", y la frontera como "espacio socialmente construido". La interpretación de la frontera como es- pacio absoluto apareció a mediados del siglo XIX y se mantuvo vigente hasta prácticamente la década del sesenta, sobre todo en los campos de la geografía política y la geografía histórica. Para definir el concepto frontera, los principales autores de esta postura recurren a la categoría "territorio" cuando se refieren a divisiones internacionales o políticoadministrativas, y utilizan las categorías zona y región cuando aluden a un espacio de interacción entre comunidades humanas diferenciadas. En seguida, vinculan cada una de esas categorías a ciertos procesos sociales que, desde su perspectiva, inciden, determinan y definen la naturaleza humana de la frontera. Finalmente, centran su atención en procesos de tipo jurídico-político y estratégico-militar y, en consecuencia, identifican al Estado y al "pueblo nacional" como los actores que actúan sobre y en el espacio de frontera.

Por su parte, la postura de la frontera como espacio socialmente construido es de aparición relativamente reciente, pues es producto del giro teórico y metodológico ocurrido en la geografía humana en la década del setenta, una postura teórica encabezada por los movimientos académicos conocidos como geografía radical y geografía humanista. En términos generales, los autores de estos movimientos conciben a la frontera como un espacio cambiante, de manera que la definición del concepto es construida por las prácticas sociales y no por la categoría geográfica con la cual se la vincula. Afirman que los fenómenos jurídico-político y estratégico-militar no son los únicos 
que inciden y caracterizan a la frontera, pues existen otros de tipo económico, poblacional y sobre todo cultural que también son relevantes. Por último, rechazan que sean el Estado y el "pueblo nacional" los actores que definan la existencia de la frontera.

Este artículo explica las definiciones del concepto frontera en las dos posturas antes mencionadas. También identifica y discute las principales tesis de la frontera que han sido elaboradas en ambas posturas a lo largo del siglo XX. Adicionalmente, el texto proporciona algunos ejemplos de estudios sobre las fronteras de América Latina que se han apoyado en las tesis en cuestión.

\section{La frontera como espacio absoluto}

La idea del "espacio absoluto" ha estado presente en el pensamiento geográfico desde la aparición de la geografía humana a mediados del siglo XIX, hasta prácticamente la década de 1960 . Su base epistemológica se encuentra en la filosofía del organicismo-mecanicista, importada de la sociología (Santos, 1978, p.46) y el Naturalismo, y según la cual cada espacio geográfico es un "receptáculo infinito". Su existencia física es independiente de los fenómenos sociales que ahí ocurren, pues responde a sus propias leyes de orden natural. El espacio geográfico es transformado por la acción humana, pero solo en su apariencia, nunca en su esencia. Una consecuencia de esa transformación es el espacio frag- mentado, dividido y diferenciado. Por último, el espacio absoluto es un simple contenedor de objetos, seres humanos y actividades sociales, y son precisamente las actividades sociales el elemento utilizado para diferenciar y clasificar al espacio geográfico. (Sáenz, 1977, p. 355-356; Santos; 1978, p. 50-51)

Para la postura mecanicista-organicista en la geografía humana, el espacio es el objeto de estudio de la disciplina, y el método es la descripción de los diferentes espacios geográficos y los acontecimientos y procesos que ahí tienen lugar. Simplificando al máximo esta idea, se trata de la tesis central de la geografía descriptiva establecida por Karl Ritter (1862) a mediados del siglo XIX. En la geografía descriptiva, la idea del espacio absoluto se convirtió en un elemento central de su discurso geográfico y en una manera aceptada de conceptualizar el espacio y los objetos y acontecimientos que ahí existen. (Curry, 2002, p. 507)

La geografía humana de finales del siglo XIX consideraba la frontera como un fragmento del espacio absoluto, un escenario en donde ocurren procesos sociales y que a pesar de la acción humana es inmutable, pues se rige por sus propias leyes. Para caracterizar y clasificar la frontera, recurría a diferentes categorías geográficas (región de frontera, área de frontera, zona de frontera, espacio de frontera, etcétera), a las características de la geografía física en donde fue instalada (frontera terrestre, frontera marítima; frontera pluvial, etcétera) y a las actividades o prácticas sociales domi- 
nantes (frontera agraria, frontera minera, frontera ganadera, frontera militar, etc.).

Los primeros estudios de las fronteras en la geografía humana fueron dominados por las interpretaciones de corte histórico y geopolítico, precisamente en los entonces nuevos campos de la geografía política y de la geografía histórica. En estas interpretaciones, la definición frontera parte de la categoría territorio, espacio considerado la variable dependiente de una categoría mayor: la "región estratégica". La frontera es diferente del límite, pero ambos cumplen funciones comunes en torno a la defensa del territorio. (Delgado, 2003, p. 23-24; Curry, 2002, p. 507)

Los autores que construyeron definiciones de la frontera como espacio absoluto (Fawcet, Ratzel, Vallaux, Ancel, Curzon, e incluso el historiador Frederick Jackson Turner) coinciden en que las "fronteras estratégicas" son las que verdaderamente afectan las dimensiones de los territorios y, por extensión, la existencia del Estado. Se entiende por frontera estratégica la franja de terreno, zona o región de defensa del territorio, adyacente al límite territorial y que sirve además para ubicar la contigüidad entre las diferentes regiones estratégicas. A su vez, la región estratégica identifica fragmentos de la Tierra que van desde una parte diferenciada dentro de un mismo territorio o grupos de territorios, hasta grandes porciones del planeta, cuya función es garantizar la seguridad de los Estados en su relaciones de poder mundial. Ni en lo territorial ni en lo global, el límite territorial tiene mayor importancia, pues no es la base sobre la cual los Estados toman decisiones de política internacional; las fronteras estratégicas son las únicas que cumplen esta función.

A pesar de dicha coincidencia, en la concepción del espacio absoluto persisten diferencias en cuanto a las funciones y los fenómenos sociales considerados para definir y clasificar a las fronteras. Por ejemplo encontramos autores que descubren en las fronteras funciones de contención de las amenazas externas, y dado que son los fenómenos jurídico-políticos los que caracterizan a los territorios, por extensión también lo hacen para la frontera. Esta forma de interpretación es elaborada frecuentemente por académicos especializados en geografía política, para quienes el territorio es una porción del planeta en donde ocurren interacciones jurídico-políticas entre los Estados y la frontera es concebida como zona.

Por lo anterior, podemos identificar dos formas de interpretación de la frontera como espacio absoluto. La primera fue realizada en la geografía política clásica, la segunda, las fronteras estratégicas, en la geopolítica clásica. Para los autores de la primera disciplina, como se dijo anteriormente, la frontera está caracterizada por interacciones de tipo jurídicopolítico, las categorías geográficas que la representan son territorio y zona, y el principal responsable de su creación es el Estado. Las dos variantes de interpretación de las fronteras en la geografía política clásica son la del manual escolar (frontera como parte del territorio) y 
la descriptivo-sintética (frontera como zona).

Por su parte, para los autores de la geopolítica clásica, la categoría geográfica central es la región, espacio en el que ocurren relaciones de poder entre los Estados. Se trata de la idea de la frontera como región estratégica, de la cual se desprenden cuatro tesis claramente diferenciadas: la frontera como la piel de un organismo vivo u organicista, la frontera como "zona de interpenetración, las "fronteras dinámicas" y las fronteras extendidas.

\section{La frontera como zona}

La geografía política tradicional es por naturaleza descriptiva. Podemos encontrarla en dos versiones: la del manual escolar y la descriptivo-sintética. De la primera versión es suficiente con decir que concibe a la frontera como un lugar (área limitada o porción concreta del espacio con un alto grado de simbolismo) del territorio y que los fenómenos que la determinan son de naturaleza jurídico-política. Esta versión aparece fundamentalmente en los manuales escolares de geografía política y se distingue por su carencia de análisis. En estos trabajos, la frontera es identificada como la línea de separación de territorios nacionales que puede ser ubicada con exactitud en la geografía del planeta, por lo tanto, también es representable en mapas. Se le clasifica por el tipo de espacio que delimita (terrestre, marítimo o aéreo) y por la marca o factor geográfico de re- ferencia (natural, geodésica o geométrica) -curiosamente estas clasificaciones elementales provienen de los tratadistas de derecho internacional-. Por último, para esta versión, el actor que determina la existencia de la frontera es el Estado.

Para la segunda versión, la descriptivosintética, la frontera es diferenciada del límite territorial de los Estados, pues ambos son espacios de naturaleza distinta: la frontera es un área de contacto entre poblaciones humanas, mientras que el límite es el lugar que marca la diferencia espacial de jurisdicciones estatales. Es por eso que la frontera es un espacio geográfico complejo en donde ocurren fenómenos sociales de naturaleza diversa y que tienen incidencia en el desarrollo de los Estados.

En la versión descriptivo-sintética de la geografía política encontramos la definición de la frontera como una zona. El autor que desarrolló esta tesis fue el profesor de geografía Charles Bungay Fawcett (1918). Para este antiguo profesor de Oxford y discípulo de Halford Mackinder, en los orígenes de la civilización humana, la frontera en su forma natural fue una barrera de separación entre culturas y razas. Con el crecimiento de la población y el desarrollo de habilidades para el control de mayores áreas terrestres, la frontera fue transformada en una zona de contacto, la mayoría de las veces conflictiva. En la época moderna, la frontera como zona de contacto implica una presión mayor para determinar con exactitud el límite territorial entre los Estados. (p. 15) 
La frontera es "una zona de separación entre dos áreas de población más o menos homogénea y usualmente densa". La efectividad para separar tales áreas depende de las características de geografía física en donde es instalada, de su poblamiento y de los avances civilizatorios alcanzados por sus pueblos. Una población homogénea es una unidad permanente, lo cual, dicho en otros términos, es una nación. Para Fawcett, ninguna discusión sobre las fronteras puede estar completa si no se consideran las entidades nacionales (1918, p. 16). En este sentido, el Estado no es el único agente que interviene en la creación de fronteras.

En su análisis, Fawcett enfatiza que la principal característica de la frontera es la combinación de una "franja de frontera (frontier)" (franja equivalente a zona) y la línea del límite territorial (Boundary), aunque no explica por qué ni cuándo la frontera adopta alguno de estos rasgos. La "franja de frontera" es un espacio transición entre dos regiones fuertemente contrastadas, en tanto que el límite territorial es la línea de separación de esas regiones. Es por ello que la frontera tiene un carácter zonal, lo que puede observarse en las fronteras de áreas naturales, así como en las zonas raciales y lingüísticas. (1918, p. 20-21)

La influencia de la tesis de la frontera de Fawcett puede ser identificada en algunos geógrafos latinoamericanos. Podemos mencionar la idea de la frontera entre las regiones de América sajona e Hispanoamérica, elaborada por el geógrafo
Salvador Massip Valdés (1931). Para el profesor y diplomático cubano, entre ambas regiones hay una zona de contacto, una región fronteriza, (zona y región como sinónimos), una zona de transición, que está constituida por México, Cuba, Haití, República Dominicana y Puerto Rico. Es una marca que corre de Este a Oeste, en la cual chocan la cultura y los valores de dos civilizaciones, la hispánica y la anglosajona. Para Massip, el Caribe constituye el área crítica del Nuevo Mundo, pues es ahí donde ocurre el contacto y la presión más intensa de la zona de frontera entre las civilizaciones hispánica y sajona.

\subsection{La frontera como región estratégica}

El segundo grupo de interpretación de la frontera como espacio absoluto es la que centra su argumentación en el concepto de región estratégica. Es precisamente en esta perspectiva en donde se ha realizado el mayor número de estudios teóricos sobre las fronteras, e indiscutiblemente ahí están muchos de los autores más influyentes en la materia. En la lista aparecen escritores de origen intelectual y profesional tan diversos como Friedrich Ratzel, Karl Haushofer, Lord Curzon, T. S. Holdich, Camile Vallaux, Jean Jaques Ancel, Isahia Bowman, Whitmore Boggs, Owen Lattimore y Jaime Vicens Vives. Todos ellos son los ídolos de la tribu que estudia las fronteras estratégicas. Algunas perspectivas geopolíticas que han influido en los estudios de las fronteras en América Latina son: la tesis organicista de la frontera de Friedrich Ratzel, 
Johan Rudolf Kjellén y Karl Haushofer; la tesis de la "frontera como zona de interpenetración" de Camille Vallaux; la tesis de "las fronteras dinámicas" de Jean Jaques Ancel y la tesis de las "fronteras extendidas" de Lord Curzon.

\subsection{La tesis organicista de la frontera}

Los primeros acercamientos a la concepción geopolítica de la frontera se encuentran en las tesis geográficas de Karl Ritter. Este famoso geógrafo alemán adoptó para la geografía el concepto de "la Tierra como organismo vivo". Se trata, dice Ritter, de un todo orgánico dividido en espacios geográficos, cada uno de los cuales es el campo donde las naciones deben resolver su propio destino. Esos espacios dependen entre sí, de manera que forman una unidad, un organismo, un Cosmos. Las divisiones naturales del planeta existían antes de que el hombre hiciera la división del territorio donde vive. Las divisiones humanas de su territorio, es decir los límites, fueron acomodados de manera arbitraria, por lo que muchas veces las líneas de división no representaban realmente el tamaño del “cuerpo nacional". (Ritter, 1862, p. v-x)

El argumento anterior es llevado por Friedrich Ratzel mucho más allá de la simple interpretación geográfica y le da un sentido práctico. Efectivamente, Ratzel transforma la idea de la "Tierra como organismo vivo" en un modelo estratégico de acción política para el Estado alemán. Para él, si bien las características del espacio determinan el destino de las naciones, los Estados pueden controlar y utilizar los factores geográficos en su propio beneficio; la geografía política aplicada (geopolítica) es la ciencia que explica cómo hacerlo. (Vallaux, 1914, p. 3; Weigert, 1956, p. 77)

Ratzel fundamenta su idea de la frontera en la "ley de los espacios crecientes" que formula en su ensayo Sobre las leyes del crecimiento espacial de los Estados, publicado en 1896, un año antes de que apareciera su obra maestra Geografía Política. En dicho ensayo, Ratzel resalta la importancia del Lebensraum (espacio vital). A partir de este concepto, y apoyado en varios casos empíricos sobre el crecimiento y la expansión histórica de los Estados, concibe sus sietes leyes de la expansión territorial de los Estados, la primera de las cuales justifica la expansión de los Estados poderosos en detrimento de sus vecinos más débiles. (Vicens, 1961, p. 45)

Para Ratzel, la "ley de los espacios crecientes" no debe ser considerada un objetivo de los Estados. El crecimiento tiene un límite, pues un imperio con grandes dominios territoriales debe poseer también una gran fuerza militar para conservarlos. Tampoco un gran territorio en sí mismo hace fuerte a los Estados, pues lo que realmente le da fuerza es la ocupación y la distribución de la población nacional en todo ese espacio. Señala que cuando la expansión del espacio vital va unido al crecimiento de la población políticamente organizada y arraigada al suelo, entonces puede descubrirse la evolución histórica de una nación. (Wiegert, 1956, p. 76-77) Ratzel afirma que el espacio de los Es- 
tados aumenta con el crecimiento de la cultura, pero también crece mediante la fusión y la absorción de unidades políticas menores. La frontera es "el órgano periférico" del Estado, o "la piel del Estado"; es la institución que refleja la expansión del territorio. El Estado intentará agregar a su territorio solamente aquellas áreas políticamente valiosas, por ejemplo, áreas costeras, cuencas de ríos, llanuras y regiones ricas en recursos naturales (Wiegert, 1956, p. 79). La expansión de los espacios, según Ratzel, se ha manifestado históricamente en un proceso que va de un Estado terrestre, pasa a otro fluvial y luego a otro marítimo. Este proceso también es identificado por Camille Vallaux, quien lo define como "la ley de continuidad histórica de los Estados complejos”. (1914, p. 3)

Finalmente, para Ratzel, la expansión de los espacios está determinada por caracteres (factores) físicos como el clima, el relieve del suelo o la posesión de costas, ríos y bosques, etcétera. Según las circunstancias históricas y las contigüidades geográficas entre pueblos, esos factores impiden o ayudan a la formación de Estados, pero de ninguna manera determinan el nacimiento de este ni le hacen perecer. El desarrollo y la permanencia de un Estado dependen de la posesión de un espacio (Raum) y de la ubicación (Lage) de este en el globo terráqueo. (Vallaux, 1914, p. 149)

La tesis geopolítica de las fronteras de Ratzel es retomada y, en algunos casos, ampliada -e incluso distorsionada- por varios de sus estudiantes más notables.
El discípulo más cercano de Ratzel fue la geógrafa estadounidense Ellen Churchill Semple, a quien se le conoce en los países de habla inglesa por la difusión de las ideas etnográficas y antropológicas de su maestro. El trabajo más importante de Ellen C. Semple es Influences of Geographic Environment (1911), en donde retoma y simplifica los planteamientos de Antropogeographie de Ratzel (Wiegert, 1956, p 72). Ellen C. Semple dedica un capítulo completo de su libro al asunto de las fronteras y los límites territoriales. En síntesis, afirma que las fronteras son zonas de contacto y de transición donde operan fuerzas centrípetas contra los pueblos más débiles. Distingue cuatro tipos de frontera, cada una con un diferente grado de importancia en la historia de los pueblos o los Estados, estas son: racial, cultural, lingüística y política. Por último, también considera la frontera como una zona de expansión política, aunque asegura que la expansión cultural es la más importante. (Semple, 1911, p. 150-175)

Los difusores más conocidos de las ideas geopolíticas de Ratzel fueron sus alumnos Rudolf Kjellén y el "mayor general profesor" Karl Haushofer. La "ley de los espacios crecientes" es retomada y desarrollada por Rudolf Kjellén -quien además la convirtió en la base de su concepto de geopolítica- y transformada en el "corazón" del pensamiento geopolítico de Karl Haushofer. Kjellén lleva al extremo del organicismo esta ley, al afirmar: "el Estado emerge como una manifestación biológica o forma de vida”. (Tunander, 2001, p. 52-53). 
Por su parte, Karl Haushofer asegura que la frontera es la expresión de una línea de división entre naciones. Esta idea la desarrolla en el libro Grenzen (Fronteras), publicado en 1927. En este texto rechaza que las fronteras sean rígidas e inmutables, tal y como lo establece el concepto geopolítico de Lebensraum formulado por Ratzel. Haushofer afirma que los diplomáticos no pueden construir un espacio vital mediante tratados de fronteras, ni tampoco desarrollar la "conciencia e instinto fronterizo" en la población nacional. Debido a esto, la política de Estado puede verse truncada si sólo se observa la frontera como un eterno límite territorial. Las fronteras no son organismos muertos, por el contrario, son organismos vivos que se expanden y se contraen "del mismo modo que la piel y otros órganos protectores del cuerpo humano" (Wiegert, 1956, p. 85-71). Haushofer también compara la frontera con "la piel periférica" del cuerpo político, "una parte respiratoria del organismo vital". Por lo tanto, un pueblo no debe resignarse a vivir en un espacio estrechado por sus vecinos, por el contrario, el Estado debe rechazar los "límites indefensos" de manera que alcance a ocupar lo que por naturaleza conforma su espacio vital. (Haushofer, 1975, p. 85)

La influencia de la tesis organicista de la frontera de Friedrich Ratzel, Johan Rudolf Kjéllen y Karl Haushofer, es significativa para el estudio de la frontera en Sudamérica y comparativamente menor en el caso de México (Gómez, 2006). Esta tesis fue acogida principalmente por los coroneles geógrafos sudamericanos y algunos académicos (Alberto Escalona Ramos, en México; Everardo Backheuser, en Brasil), quienes la adoptaron convenientemente a sus percepciones de lo que eran o deberían ser las fronteras de sus respectivos países. No sometieron a revisión crítica los conceptos geopolíticos de Ratzel, simplemente los retomaron para elaborar o proponer políticas militares de control y seguridad territorial y de la frontera. La definición geopolítica que dieron al concepto frontera fue una combinación acrítica de conceptos provenientes de diferentes escuelas (alemana, francesa, inglesa y estadunidense), en la que no hubo ejemplos empíricos de la región para sustentar sus afirmaciones.

\subsection{Las tesis de las fronteras como "zonas de interpenetración"}

Otro autor que concibe la frontera como espacio absoluto fue el geógrafo francés Camile Vallaux. En su libro El suelo y el Estado (1914), formula su teoría de la "frontera como zona de interpenetración", con la cual pretende hacer una crítica a la teoría organicista de Ratzel. Sin embargo, en esta teoría no se somete a juicio crítico profundo la tesis de la frontera del profesor alemán, incluso concuerda con él en diferentes postulados.

Para Vallaux, la frontera es una zona de interpenetración y separación al mismo tiempo. Ahí se presentan con suma intensidad las fuerzas de desunión y de fusión entre grupos sociales; esto último, dice, las hace interesantes para ser 
estudiadas. También la define como "una transcripción concreta sobre el mapa" donde se agrupan zonas contrastantes, así como contactos e interpenetraciones que producen los movimientos políticos. (Vallaux, 1914, p. 375, 406)

Vallaux concibe la frontera como un término relativo, es decir, que varía en el tiempo y en el espacio, así como en sus usos sociales y funciones. La frontera como línea de demarcación es una especie de barrera ideal, "que no detiene ni retarda ningún tipo de interpenetración". Las interpenetraciones (movimientos de personas, ideas y mercancías; caminos, canales, ferrocarriles) suelen borrar la existencia de los límites de los Estados. Parecería entonces que las fronteras son simples añadidos sin importancia de los territorios. Sin embargo, dice el geógrafo francés, la frontera no debe ser considerada solamente como una línea de separación territorial de los Estados, sino como zonas adyacentes a esos límites internacionales. (Vallaux, 1914, p. 89, 374-75)

\subsection{La tesis de "las fronteras dinámicas"}

A diferencia de Camille Vallaux, su compatriota, colega y contemporáneo, Jean Jaques Ancel, no solo es contundente en la crítica al pensamiento geopolítico de Ratzel, sino que además brinda una concepción original del concepto frontera. Jean Jaques Ancel -el discípulo más distinguido de Vidal de la Blache- publica el ensayo Géopolitique (1936), el cual en realidad es un estudio teórico de la frontera, pues este concepto es el eje de toda la argumentación del texto. Ancel publica posteriormente Géographie des frontières (1938), en donde profundiza y amplía su tesis de las "fronteras en equilibrio". Ambos trabajos avivaron el debate en torno a las fronteras entre las escuelas geopolíticas francesa y alemana. (Sidaway, 2005, p. 3)

Géopolitique inicia con una crítica a la escuela geopolítica alemana -calificada por Ancel como una ideología del expansionismo militar alemán- y especialmente a la idea geopolítica de frontera creada por Ratzel. Para Ancel, la frontera ha sido en el curso de los tiempos una palabra que recupera una multitud de realidades. Ha sido "una mirada del espíritu nacional que se dibuja en un mapa" (el territorio como el cuerpo de la patria) pero que no se modela jamás en la naturaleza. Históricamente la frontera ha sido un concepto más bien ideal antes que real, y cuando los gobiernos empezaron a relacionarlo con la idea de seguridad del Estado, adquirió una noción relativa que ha variado con el tiempo. (Ancel, 1936, p. 56-57)

Según Ancel, la frontera no posee un valor absoluto, sino relativo. Este valor depende de la función que le ha sido asignada por el grupo social en el poder, que divide y separa el territorio al cual se encuentra atado. A partir de esto, identifica dos formas de definir el concepto frontera: la determinista, según la cual, las características físicas del suelo son las que establecen y determinan la existencia de la frontera; y la noción dinámica que concibe la frontera como 
producto de la acción humana. (Ancel, 1936, p. 57-59)

Finalmente, para Ancel, la frontera toma sus calificativos según las coyunturas políticas. En sí mismas, las fronteras no son "buenas" ni "malas", sino que su valor es asignado por los grupos sociales, particularmente por los que detentan el poder. De esta manera, esos grupos son los que califican las fronteras como lugares de tensión; zonas o regiones muertas, vivas, vacías; regiones económicas, militares, estratégicas, lingüísticas, etcétera. Estos calificativos provienen de factores de la acción humana, no del lugar en el que están ubicadas.

\subsection{La tesis de las "fronteras extendidas"}

George Nathaniel, Lord Curzon, "el santo patrono de los Estados tapón", fue geógrafo e historiador, además de un estudioso de las fronteras imperiales de Gran Bretaña. Fue considerado en los círculos políticos de su país como un gran conocedor práctico de las fronteras como espacios de seguridad y protección de los territorios coloniales. Probablemente el primer intento por abordar de manera detallada las fronteras políticas, su tipología y su historia fue realizado por Lord Curzon en su ensayo Frontiers (1907). Si bien anteriormente Ratzel, Kjellén e incluso Frederick Jackson Turner ${ }^{2}$-autor

2 Frederick Jackson Turner es el autor más influyente, o por lo menos el más citado, entre los estudiosos de las fronteras en la historiografía y la geografía latinoamericanas. Sus tesis sobre la frontera son de corte historiográfico, aunque tienen mucha similitud con la interpretación geodeterminista de Ratzel. La adaptación de las tesis de Turner al estudio del famoso artículo "La frontera en la historia americana" - habían abordado el concepto frontera, lo hicieron como parte de estudios más generales sobre la geografía del territorio de los Estados o como producto de la historia política de un solo país.

Otro aspecto importante de las ideas de Lord Curzon es la habilidad con la que aborda el tema de las fronteras. Esta habilidad provino de su labor como negociador de los límites territoriales del imperio británico en Asia, de su trabajo como virrey en la India y de su actividad diplomática en las negociaciones de paz de la Primera Guerra Mundial.

El trabajo más conocido de Lord Curzon es Frontiers (1907), en donde el concepto central es la "frontera extendida". Este tipo de frontera, dice, estaría definida por diferentes modelos de control extraterritorial, entre los que aparecen las "zonas de seguridad", las zonas de influencia, los "Estados tapón", el protectorado y la "zona de interés". Su existencia se debe fundamentalmente a la necesidad de las potencias imperialistas de conservar sus posesiones coloniales y mantener sus capacidades de poder en la política mundial. (Curzon, 1907, p. 36)

No es posible asegurar que las ideas de Lord Curzon hayan motivado en América Latina el surgimiento de un enfoque específico sobre las fronteras, sin em-

de las fronteras latinoamericanas puede observarse, por ejemplo, en los trabajos de los geógrafos Pierre Mombeig (1952), María Cristina Hevilla (2001), Carlos Reboratti y Beatriz Vitar Mudski (1997), entre otros. 
bargo, una de sus afirmaciones sirve de epígrafe para artículos publicados por los académicos de la región: "Las fronteras son el filo de la navaja sobre el cual están suspendidos los asuntos modernos de la guerra o la paz, la vida o la muerte de las naciones (...)”. (p. 33-34)

\section{La frontera como espacio socialmente construido}

Hacia mediados del siglo XX, la geografía humana entró en una etapa de renovación teórica y metodológica. Se trató de una reinvención de la geografía como ciencia social, inspirada en el interés por desarrollar un cuerpo teórico y metodológico propio. Es el auge de la geografía cuantitativa enfrentada a la geografía descriptiva. El desarrollo de los grandes centros urbanos (las megalópolis de Jean Gottmann) descubrió nuevos temas de investigación en donde se podían aplicar modelos estadísticos y matemáticos y técnicas de otras teorías sociales, especialmente de la teoría general de sistemas y el estructuralismo. (Delgado, 2003, p. 34-35; Pillet, 2004, p. 142; Kwan, 2004, p. 757 ; Santos, 1978, p. 71)

La geografía cuantitativa fomentó el surgimiento de una gran cantidad de "geografías" -e igual número de teorías y métodos de análisis - una para cada fenómeno que pudiera ser cuantificado y representado en un mapa. Curiosamente, las fronteras no fueron un fenómeno de interés tan grande como para crear su propia geografía especializada. El desarrollo de la corriente cuantitativa coincide con el abandono del estudio geográfico de las fronteras.

En efecto, con el avance de la geografía cuantitativa decayó el interés por el estudio de las fronteras, especialmente para los investigadores de la geografía política, la geopolítica y la geografía histórica. En esos campos de la geografía humana se consideraba que lo realmente importante eran los conflictos territoriales y los secesionismos étnicos. Observaban que las dos grandes potencias lograron, sin proponérselo, mantener sin cambios las fronteras territoriales en Europa, de manera que estudiar las fronteras era un asunto de poca importancia (Raffestin, 2007 , p. 122). Pensaban que las fronteras eran una simple línea de división de jurisdicciones estatales, donde terminaba el territorio de un Estado y comenzaba el de otro. Finalmente, sostenían que "las fronteras son instituciones establecidas por decisiones políticas y regidas por textos políticos”. (Anderson, 1997, p. 15)

Sin embargo, en la década de 1970 se gestó un "giro teórico" y metodológico en el campo de la geografía humana, conducido por dos movimientos académicos que denominaron a sus propuestas "geografía radical" y "geografía humanista", respectivamente (Delgado, 2003, p. 79; Zusman, 2002, p. 25). Este giro teórico fue en respuesta, por un lado, a las posturas hegemónicas de la geografía cuantitativa, por el otro, a los profundos y rápidos cambios en los espacios humanos y en la sociedad mundial. Consistió en el reconocimiento de que la complejidad del mundo requiere para su análisis 
de nuevos enfoques y marcos teóricos multidisciplinarios.

El desarrollo de la geografía crítica y la geografía humanista ocurrió en universidades anglosajonas, principalmente. Al tiempo que estos movimientos se expandieron hacia otras instituciones y centros de investigación del mundo, diversificaban sus temáticas y metodologías de análisis en un abanico amplio de posturas teóricas (Zusman, 2002, p. 28). Tales posturas han adoptado nombres como geografía crítica, la geografía poscolonial, la nueva geografía cultural, geopolítica crítica, etcétera, la mayoría de las cuales han recuperado el interés por los estudios de la frontera. Cada enfoque ha buscado renovar la investigación sobre el tema, pero ya no considerando este espacio como un contenedor de procesos sociales, sino como un "espacio socialmente construido".

El interés renovado por el estudio de la frontera en la geografía humana fue estimulado por diferentes acontecimientos políticos internacionales de profunda trascendencia histórica. Se trata de acontecimientos como: la desintegración de la Unión Soviética y de su bloque político militar; el resurgimiento de viejos conflictos étnicoterritoriales y de delimitación fronteriza; el avance de los procesos de integración económica mundial y la formación de bloques económicos; los fenómenos económicos, sociales y tecnológicos de alcance global parecían debilitar las capacidades de los Estados para controlar y vigilar sus fronteras; y las reformas de descentralización admi- nistrativa emprendidas en varios países que replantearon la necesidad de modificación de las divisiones administrativas internas. (García, 2003, p. 68)

Así pues, los movimientos radical y humanista han recuperado la vieja preocupación de la geografía humana por los estudios de la frontera, pero ahora por aquella manifestada en un nuevo contexto histórico y que será analizada mediante un diálogo permanente con otras disciplinas sociales. La geografía disidente, como también se les conoce a estos movimientos, ha discutido la validez de viejos conceptos y ha explorado facetas de la frontera abordadas en otras ciencias sociales. En este sentido, no se trata solamente de explicar las manifestaciones de un viejo objeto de estudio, sino hacerlo a través de nuevos marcos conceptuales y en colaboración con otras ciencias. No obstante lo anterior, muchos geógrafos disidentes aún consideran que el estudio de la frontera no es un campo dentro de la geografía humana, sino una línea de investigación tradicional de disciplinas como la geografía política, la geografía histórica y la geografía cultural. (Dear, 1988, p. 263)

El concepto de frontera desarrollado por las geografías disidentes tiene una marcada pluralidad de definiciones, las cuales dependen del campo geográfico desde el cual se la estudia. Nuevamente, las múltiples definiciones del concepto están determinadas por las categorías geográficas desde la cual se la interpreta, por los procesos sociales que inciden sobre los espacios de frontera y los actores que 
participan en esos procesos. La diferencia radica en cuál de esos elementos predomina en la definición.

De esta manera, dentro de la postura de la "frontera como espacio socialmente construido", podemos identificar tres tesis: la frontera como producto del sistema social e instalada a partir de relaciones de poder; la frontera como espacio poscolonial, situación generada por la mundialización económica; la frontera como espacio simbólico, percibido y representado por la racionalidad moderna. Veamos de manera general cada una de esas tesis.

\subsection{La frontera como producto del sistema social}

La tesis de la frontera como sistema social centra su análisis en los sujetos y las acciones humanas, antes que en los espacios. Para esta concepción, la frontera es un espacio histórico, producido socialmente por el conjunto de relaciones sociales, económicas, políticas y culturales, entre los individuos, grupos e instituciones. Es un espacio que puede ser explicado por las relaciones sociales de producción que lo organizan, por las acciones de dominación y de poder que ahí tienen lugar, y por las representaciones que de este tienen los sujetos que lo viven y los grupos que tienen el poder político y económico para transformarlo. La frontera es el fragmento de un espacio mayor, el territorio, que ha sido estructurado mediante relaciones sociales de producción dominantes.
Las ideas de David Harvey, Henri Lefebvre y Milton Santos son la base de esta tesis. Estos autores, los más importantes dentro del movimiento de la geografía radical, no dedicaron algún trabajo específico al estudio de las fronteras, sino que contribuyeron con buena parte del marco conceptual que hoy forma parte del discurso científico en la geografía disidente.

Para David Harvey, conceptualizar la forma que adopta el espacio se logra descubriendo las prácticas sociales que ahí se realizan, en particular las derivadas del modo de producción dominante. Comprender verdaderamente el espacio, solo es posible a partir de una geohistoria, lo que implica el conocimiento de los procesos sociales involucrados en su producción. (Harvey, 1977, p. 3-6; Delgado, 2003, p. 90; Martin, 2006)

Por su parte, Henri Lefebvre señala que "el modo de producción organiza - produce- al mismo tiempo que relaciones sociales, su espacio y su tiempo". En este sentido, el espacio es un producto social. El espacio así producido sirve también de instrumento al pensamiento como a la acción. Es, al mismo tiempo que un medio de producción, un medio de control, por lo tanto de dominación y de poder. El espacio se explica mediante la idea de la "triplicidad del espacio", es decir, "la distinción entre el espacio percibido, el espacio concebido y el espacio vivido". Son las representaciones del espacio vinculadas al modo de producción dominante. (1974, p. 38-39) 
El objetivo de la geografía humana, dice Lefebvre, es hacer visible para la teoría social el espacio de la vida social, es decir, "el espacio socialmente producido por el conjunto de las relaciones sociales, económicas, políticas y culturales entre los individuos y los grupos". El espacio es un producto social, que a la vez es "concretizado", creado y ocupado progresivamente por un capitalismo que avanza. El espacio de la vida social es fragmentado en porciones, homogenizado con marcas distintivas; organizado en posición de control y alargado a escala global. Se trata pues de un espacio fragmentado, homogenizado y jerárquicamente estructurado por las relaciones sociales de producción. (p. 86-88.)

Por último, Milton Santos es aún hoy el geógrafo latinoamericano que más trabajó en elaborar una concepción del espacio como construcción social. Este ilustre profesor brasileño plantea que producir mercancías y producir espacio son dos actos indisociables, pues al producir, la sociedad transforma la naturaleza primera (naturaleza bruta, ecosistema salvaje) y, en consecuencia, crea una segunda naturaleza, un espacio social. (1978, p. 203)

El espacio social es un reflejo de las relaciones sociales de producción, de los procesos de intercambio de las mercancías y de la tecnología. Es por eso que la expansión mundial del modo de producción capitalista impulsa un espacio social de alcance mundial, o espacio total. Ahora bien, la idea de espacio total es inseparable, dice Milton Santos, de las estructuras sociales. El espacio social es una estructura social, y como tal también contiene subestructuras. Las localidades, regiones, zonas y otros tipos de subespacios -entre los que podríamos incluir a las fronteras- son espacios funcionales de procesos globales. (1978, p. 219)

El proceso de construcción del espacio total se inició hacia principios del siglo XVI. No se trata de un proceso que lleva a la unificación de los espacios locales, sino de diversificación y fragmentación de la geografía del planeta. Uno de esos fragmentos es el territorio, una parcela de la Tierra indispensable para que el Estado realice sus funciones: mediar entre las fuerzas externas y los espacios locales considerados de un alto valor económico por esas mismas fuerzas externas. (1978, p. 223-226)

El alcance espacial de las funciones del Estado está definido por los límites territoriales. Un mismo territorio no conserva los mismos límites a lo largo de su historia, pues estas pueden cambiar por acuerdo, pacífico o impuesto, de los Estados. Durante ciertos períodos de tiempo, la línea de separación territorial parece inamovible, fija, y así lo expresan los sujetos del poder, algunos defendiendo la ubicación del límite en ese momento, otros sosteniendo eternas disputas territoriales. (1978, p. 233)

La tesis de la frontera como producto del sistema social ha sido desarrollada en los campos de la geografía política y la geografía histórica, principalmente. Uno de los autores que ha desarrollado 
estudios del territorio y las fronteras de América Latina en el campo de la geografía política, es Jonathan Barton. Fuertemente influenciado por el marxismo y el poscolonialismo, en su libro Political Geography of Latin America (1997), hace una revisión general del proceso histórico de creación de las fronteras políticas, desde la era precolombina hasta la postguerra fría (mediados de la década de 1990). Barton observa que las fronteras latinoamericanas han sido sitios de conflicto potencial y apropiación por parte de diferentes sujetos sociales. También las considera como un área de actividades intra-estatales, en donde el énfasis en su localización es cada vez más importante. (p. 9)

El sistema mundial globalizado es una red de Estados nacionales que acuerdan diplomática, política y económicamente entre sí. Sin embargo, quienes trascienden la base territorial de los Estados son otros actores y procesos, por ejemplo las grandes firmas transnacionales, las cuales utilizan tecnologías avanzadas para explotar territorios y transgredir las fronteras de los Estados, y garantizarse a sí mismas altas tasas de retorno de capital. Barton señala que este proceso es definido como "desterritorialización". (1997, p. 9)

La "desterritorialización" va acompañada de dos discursos de la economía política occidental. El primero sugiere la progresiva desaparición de las fronteras políticas debido al incesante e irrefrenable flujo mundial de capitales y tecnología, lo que ha eliminado la importancia de la localización económica de los "espacios nacionales" en la toma de decisiones de las grandes corporaciones (la tesis de la desaparición de las fronteras de Kanichi Ohmae). Asimismo, los fenómenos "transfronterizos" han restado importancia a las fronteras como instrumento de control de amenazas externas (1997, p. 9-10). El segundo discurso es denominado "la idea del mundo sin ataduras", según el cual, han surgido grandes centros de acumulación de capital en territorios nacionales, pero que no están bajo el control de los Estados locales. Son formas modernas de enclaves altamente desarrolladas respecto del resto del territorio donde se encuentran. Ahí las operaciones financieras, comerciales y los movimientos de tecnología no son obstaculizados por la frontera. Estos discursos, observa Baton, dejan fuera aspectos insoslayables de la realidad latinoamericana: pobreza, marginación, exclusión, etcétera. Son ejemplos de discursos contemporáneos que reinventan la realidad espacial de América Latina, tal y como lo hicieron los conquistadores a finales del siglo $\mathrm{XV}$ : el Nuevo Mundo transformado en una extensión de Europa. (1997, p. 23)

Históricamente, para las sociedades latinoamericanas, los debates y disputas fronterizas han tenido igual importancia que otros temas de organización espacial, tales como el crecimiento de los centros urbanos, la localización de nuevos centros económicos, incluso la división territorial administrativa. Las transformaciones que ha tenido la frontera a lo largo de dos siglos, no solo ha sido consecuencia de la formación de 
Estados nacionales, sino de disputas del poder por la apropiación del espacio entre diferentes actores sociales. Para Barton, en América Latina ha existido un proceso de destrucción y reconstrucción del Estado nacional, en el que han participado diferentes actores sociales; cada uno de esos actores es un sujeto social localizado, que opera a una escala micro por la apropiación o conservación de una porción del territorio.

\subsection{La frontera como espacio poscolonial}

Según esta tesis, la frontera es un espacio híbrido, en el sentido que combina múltiples espacialidades, prácticas y temporalidades. Es también un espacio construido por las acciones del pasado, realizadas por distintos sujetos e instituciones, y subyugado a diferentes proyectos de dominación imperialista. Los promotores de esta tesis pretenden proporcionar una manera diferente para interpretar la frontera, que según ellos es una línea de investigación dominada tradicionalmente por los estudios de contenido político y geopolítico. (Zusman, 2006, p. 178)

La tesis de la frontera como representación poscolonial ha sido construida por la corriente de la geografía poscolonial, fuertemente influenciada por los trabajos del pensador de origen palestino Edward Said. Para este líder intelectual de una vertiente del movimiento poscolonial conocida como "orientalismo", la concepción del mundo colonial fue realizada en Occidente (idea del otro). Se trata de un proceso histórico que ha servido para definir la identidad de Occidente, al mismo tiempo que para justificar la dominación colonial. (Said, 1978)

La idea del mundo colonial como una representación del pensamiento occidental tuvo una amplia difusión en la geografía humana hacia la década de 1990, especialmente en los estudios sobre las imágenes de los espacios naturales y sociales realizados por el movimiento de la geografía poscolonial. Esas imágenes permiten descubrir las diferencias de género, étnicas y religiosas que son utilizadas como instrumento de dominación. El análisis de las representaciones de los colonizadores y los colonizados permite explicar el proceso de construcción de los espacios coloniales (espacios históricos) y poscoloniales. (Zusman, 2006, p. 177; Sluyter, 2001, p. 410)

Para la geografía poscolonial, la frontera es un espacio que puede ser representado como ámbito de contacto y transculturación (territorio híbrido), o bien como un espacio transformado por la acción humana (paisaje). En la frontera confluyen prácticas de sujetos e instituciones situados en distintos contextos espaciales, con otras del propio "locus" colonial. En este proceso se yuxtaponen especialidades y temporalidades diferentes (las del mundo colonial, las del mundo colonizado y las de la propuesta de "un mundo mejor"), otorgándole a la frontera el carácter de híbrido.

La geografía poscolonial identifica diferentes esquemas de conceptualización de la frontera construidas en Occidente. Se trata del determinismo ambiental, el 
determinismo cultural y el etnocentrismo. Cada uno de estos esquemas conceptuales creó discursos en los que se enfatizan relaciones sociedad-espacio fundamentadas en la diferenciación entre lo occidental y lo no occidental. Asimismo han reforzado los mitos y estereotipos de la colonización de la frontera en un "gran espacio vacío” (Sluyter, 2001, p. 415-18).

En los campos de la geografía histórica y la geografía cultural es donde más se ha notado la influencia de la tesis de la frontera como representación del espacio poscolonial. Pueden citarse como ejemplo los trabajos de Mario Cerruti (1993, 1999), Juan Viqueira (1994) y Efrén Sandoval Hernández (2008) en México; Perla Zusman (1999, 2000, 2006) en Argentina. En general, estos trabajos se caracterizan por ser estudios de casos particulares (frontera México-Estados Unidos; fronteras del Río de la Plata y la Patagonia, etcétera) en temporalidades de corta o mediana duración. Igualmente centran sus discusiones, además de las prácticas sociales, en las representaciones de los sujetos como un elemento que influye en la constitución de las fronteras.

\subsection{La frontera como espacio simbólico}

La tesis de la frontera como espacio simbólico es producto de los trabajos del enfoque posmoderno en geografía humana, particularmente por el "giro cultural" en los campos de las geografías urbana, rural y cultural. Para los geógrafos posmodernos, el ordenamiento conceptual de los fenómenos no coexiste en la naturaleza de las cosas, sino que es el reflejo de un sistema filosófico. Por ejemplo, el concepto "frontera muerta" no debe entenderse como un espacio con vida cuasi-orgánica propia, sino como parte de un sistema epistemológico que así lo interpreta. (Dear, 1988, p. 267; Gregory, 1994, p. 18)

Para la tesis de la frontera como espacio simbólico, las acciones y la vida humana tienen una expresión espacial. El espacio adopta formas imaginadas que tienen diversas repercusiones sociales. En el caso de las relaciones sociales en la frontera, por ejemplo, estas son construidas, constreñidas o mediadas por el espacio. La interacción entre actores sociales ocurre, desde luego, en un espacio geográfico determinado (lugar), sin embargo, la comprensión de estas se complica cuando se las concibe en alguna de las categorías geográficas. Las categorías geográficas (región, territorio, localidad, etc.) son divididas por fronteras físicas o humanas, las cuales delimitan los lugares en donde ocurren procesos e interacciones sociales. Las fronteras son representaciones y maneras con las cuales la gente conceptualiza determinados lugares en el espacio. (Dear, 1988, p. 269; Curry, 2002, p. 502)

Michael Curry explica cómo fueron ocurriendo desplazamientos discursivos en torno a las concepciones del lugar, región y espacio, es decir, de los discursos topográficos (arte de escribir acerca de los lugares), a los corográficos (arte de escribir acerca de las regiones) y finalmente a los geográficos (arte de escribir sobre 
la Tierra como un todo). Cada discurso puede ser identificado en las diferentes concepciones o teorías geográficas $\mathrm{y}$, particularmente, en los mapas, síntesis de esas teorías. Es la idea del mundo representado enteramente en un mapa. (2002, p. 504)

La geografía es un tipo de conocimiento que traza e interpreta líneas en un plano que representa a la Tierra, o como señala el geógrafo chileno, Hernán Santís Arenas, "los geógrafos hablan a través de los mapas". ${ }^{3}$ El lenguaje geográfico narra una historia que se expresa en un mapa. Para Derek Gregory, la deconstrucción de los mapas puede dar luz de las ideologías que están detrás de estos textos.

Para el enfoque posmoderno, lo que se debe estudiar del espacio son los lugares concretos, no nociones espaciales abstractas. El lugar no es el que se define en un concepto, sino la percepción que tienen los sujetos que viven en él. El espacio es una de las dos dimensiones de la realidad, la otra es el tiempo. El espacio es materia de interés de los geógrafos, en tanto que el tiempo lo es de los historiadores. El estudio de la frontera es un asunto temático, como lo es el estudio de las ciudades, las regiones, el territorio, etcétera. Así, la frontera es un tema que puede ser abordado en esas dos dimensiones, la espacial y la temporal. (Soja, 2001, p. 224).

3 Refiriéndose a una cita de Peter Haggett en The Geographers Art (1990): "Mucho de la Geografía es el arte de tener habilidades y conocimientos para hacer mapas" (Santís, 2002, p. 72.).
La frontera puede ser representada mediante la unidad de análisis "paisaje", el cual significa para la geografía "representación de un espacio preciso" o "espacio analizado por un observador". La representación significa una idea acordada que cierta colectividad tiene del lugar donde se encuentra. La representación proviene de la percepción del entorno, así como de los símbolos que crea alrededor del espacio. La representación y los símbolos estimulan una idea de mundo y del entorno en ese grupo social. Además de lo anterior, el grupo social actúa sobre su entorno físico transformándolo. Así, la representación y la acción sobre el entorno implica que el grupo social se reconoce parte de ese espacio, orienta sus acciones a partir de él, le da nombre, lo institucionaliza, y lo marca como su territorio. Marcar significa establecer señales físicas para delimitar el territorio del cual el grupo social ha tomado posesión. (Fernández, 2006, p. 231-32).

El territorio y la frontera son productos intelectuales y materiales del grupo social que los habita. Al igual que el territorio, la frontera es un paisaje representado por un grupo social; es un microcosmos imaginado como una representación de un cosmos mayor. Al ser un producto social cuyos integrantes se suceden de generación en generación, la frontera es una entidad de larga duración donde aparecen rasgos, objetos, imágenes y símbolos de diferentes épocas. Por eso, la frontera no puede ser reducida a un concepto, ni a una dimensión geográfica o histórica, 
sino que debe considerarse un espacio representado por una colectividad social y que puede ser interpretado de diferentes maneras.

\section{Conclusiones}

Hemos visto en este artículo que en geografía humana existen dos posturas en torno al concepto frontera: una como espacio absoluto y la otra como espacio socialmente construido. De estas dos concepciones generales se derivan las diferentes tesis de la frontera que han sido elaboradas en la disciplina.

La concepción de la frontera como espacio absoluto apareció a mediados del siglo XIX bajo la influencia del organicismo mecanicista que entonces dominaba en las ciencias en general. La premisa central de esta concepción es que el espacio geográfico es "una unidad orgánica que responde a sus propias leyes". Para los autores que cultivaron esta forma de concebir la frontera, el límite territorial es secundario frente a las fronteras estratégicas. El límite territorial solamente permite definir la forma y tamaño del territorio, pero para descubrir las amenazas sobre el espacio vital que define la existencia misma del Estado.

Los autores que escribieron sobre las fronteras estratégicas recurrieron a diferentes escalas geográficas (lugar o zona) y fenómenos sociales (culturales, políticos, económicos, geoestratégicos, etc.) para caracterizar y clasificar a las fronteras. Las fronteras como lugar, por ejemplo, se clasifican por el tipo de espacio que delimita (terrestre, marítimo o aéreo) o por el factor geográfico de referencia (natural, geodésica o geométrica). Por su parte, la frontera como zona supone un espacio de contacto entre poblaciones humanas; un espacio complejo en donde ocurren fenómenos de naturaleza diversa y que tienen incidencia directa en el desarrollo del Estado. La clasificación, por lo tanto, pueden ser fronteras culturales, lingüísticas, raciales, políticas, geoestratégicas, agrícolas, etc.

Cada intelectual geógrafo hizo su propia tipología de fronteras. Por ejemplo, Charles B. Fawcett hablaba de frontera como zona de separación y frontera, como zona de intercomunicación-presión; Camile Vallaux resaltaba la frontera como zona de interpenetración; Jean Jaques Ancel diferenciaba los tipos de frontera por los elementos a los que es vinculada por el Estado (jurídica, estratégica, nacional, cultural, religiosa, etc.); Lord Curzon las clasificaba por la época histórica en la que fueron creadas, por el espacio en el que fueron instaladas y por sus usos políticos.

Durante la década de los 60 se fue gestando el llamado giro teórico y metodológico en la geografía humana, conducido por dos movimientos intelectuales conocidos como geografía radical y geografía humanista. Ambos movimientos coinciden en que la escala de análisis de la geografía no es el "espacio absoluto" de la vieja geografía descriptiva, y se oponen a las pretensiones hegemónicas de la geografía cuantitativa. 
La geografía crítica y la geografía humanista han renovado el interés por el estudio de las fronteras, un tema ignorado por la geografía cuantitativa. Las nuevas interpretaciones de la frontera aparecen en un nuevo contexto histórico y mediante nuevos planteamientos teórico metodológicos. Asimismo se han replanteado la validez de viejos conceptos y han explorado nuevas facetas de las fronteras que anteriormente eran materia de estudio de otras disciplinas.

Las geografías radical y humanista están presentes en prácticamente todas las subramas de la geografía humana y en todas estas se estudia algún aspecto de la frontera. En este marco las "geografías disidentes" están avanzando en la redefinición del concepto frontera, siempre desde la posición de que se trata de un espacio construido socialmente.

Para finalizar, el estudio de la frontera aún no es considerada un área temática dentro de la geografía humana, como por ejemplo la geografía del turismo, del desarrollo rural o de las poblaciones, etcétera. Se le considera una línea de investigación tradicional de subdisciplinas como la geografía política, la geografía histórica y la geografía cultural. Esperemos que el avance conceptual de la frontera permita que en un futuro próximo podamos hablar en definitiva de la geografía de las fronteras. 


\section{Literatura citada}

Ancel, J. J. (1936). Géopolitique. Paris: Librairie de la Grave.

Ancel, J. J. (1938). Geographie des frontiéres. Paris: Gallimard.

Anderson, M. (1997). Les frontiérs: un débat contemporain. Cultures \& Conflicts, 26 (26). Recuperado de http://conflits.revues.org/index359.html.

Barton, J. R. (1997). Political Geography of Latin America. New York: Routledge.

Benedetti, A. (2009). Los usos de la categoría región en el pensamiento geográfico argentino. Scripta Nova. Revista Electrónica de Geografía y Ciencias Sociales, XIII (286). Recuperado de http://www.ub.edu/geocrit/sn/sn-286.htm.

Carvalho, M. B. (2006). Geografía e história, tradiçao e modernidade: fundamentos da Geopolítica contemporánea. Scripta Nova, Revista electrónica de Geografia y Ciencias Sociales, X, 218 (23). Recuperado de http://www.ub.edu/geocrit/sn/sn-218-23.htm.

Cepal/PNUMA (1983). Expansión de la frontera agropecuaria y medio ambiente en América Latina, Madrid: ONU-CIFCA.

Cerruti, M. (1993). Estudio introductorio. En M, Cerruti, M. A. González. Frontera e historia económica. Texas y el norte de México (1850-1865). México: UAM.

Cerruti, M. \& González, M. A. (1999). El norte de México y Texas (1848-1880). México: Instituto Mora.

Curry, M. R. (2002). Discursive displacement and the seminal ambiguity of space and place. En L. Lievrouw \& S. Livinsgtone (eds.). The Handbook of New Media. London: Sage Publications.

Curzon, N. (1907). Frontiers, London: s.n.

Dear, M. (1988). The postmodern challenge: reconstructing Human Geography. Transactions of the Institute of British Geographers, 13, (3).

Delgado, O. (2003). Debates sobre el espacio en la geografía contemporánea. Bogotá: Universidad Nacional de Colombia-Unibiblos.

Fawcett, C. B. (1918). Frontiers. A study in Political Geography. Oxford: Oxford University Press.

García, A. \& Bosque, J. (1985). Evolución y tendencias actuales de la Geografía Política. Documents d'Anàlisi Geogràfica, 6. 
Gómez, P. (2006). La asimilación de las ideas de Ratzel y la nueva visión del territorio mexicano. Scripta Nova, Revista Electrónica de Geografia y Ciencias Sociales, X, 218 (25). Recuperado de http://www.ub.es/geocrit/sn/sn-218-25.htm.

Gregory, D. (1991a). Geografía histórica: acción y estructura. En C. Cortez. Geografía Histórica. México: Instituto Mora-UAM.

Gregory, D. (1991b). Interventions in the historical Geography of Modernity: social theory, spatial and the politics of representation. Geografiska Annaler. Series B, Human Geography, 73, (1).

Gregory, D. \& Urry, J. (Eds.) (1985). Social relations and spatial structures. New York: St. Martin's Press.

Harvey, D. (1973). Social justice and the city. London: Edward Arnold.

Haushofer, K. (1975). Poder y espacio. En A. Rottenbach (ed.). Antología Geopolítica. Buenos Aires: Pleamar.

Hevilla, M. C. (2001). Configuración de la frontera centro-oeste en el proceso de constitución del Estado argentino (1850-1902). Tesis doctoral, Universidad de Barcelona.

Kwan, M. (2004). Beyond difference: from canonical Geography to hybrid Geographies. Annals of the Association of American Geographers, 94, (4).

Lefebvre, H. (1974). La production de l'espace. Paris: Anthropos.

Martin, J. Y. (2006). Une géographie critique de l'espace du quotidien: l'actualité mundialisée de la pensée d'Henri Lefebvre. Revue de Sciences Humaines, 2.

Massip, S. (1931). Factores geográficos de la historia de Cuba. La Habana: Imprenta Avisador Comercial.

Mombeig, P. (1952). Pionniers et planteurs de L'Etat de São Paulo. Paris: Armand Colin.

Montañez, G. \& Delgado, O. (1998). Espacio, territorio y región: conceptos básicos para un proyecto nacional. Revista del Departamento de Geografia de la Universidad Nacional de Colombia, VII, (1-2).

Newman, D. (1999). Geopolitics renaissance: territory, sovereignty and the world political map. En Newman, D. (Ed.). Boundaries, territory and posmodernity. London: Taylor \& Frank Publisher.

Nweihed, K. G. (1992). Frontera y límite en su marco mundial. Una aproximación a la "fronterología”. Caracas: Instituto de Altos Estudios de América Latina-Equinoccio Ediciones de la Universidad Simón Bolívar. 
Olivera, P. E. (2004). La concepción del espacio geográfico en la geografía crítica. En L. Llanos, M. A. Goytia \& A. A. Ramos. Enfoques metodológicos críticos e investigación en ciencias sociales. México: Plaza y Valdés.

Passi, A. (1999). Boundaries as social processes: territoriality in the world of the flows. En D. Newman (Ed.). Boundaries, territory and posmodernity, London: Taylor \& Franc Publisher.

Pillet, F. (2004). La geografía y las distintas acepciones del espacio geográfico. Investigaciones Geográficas, 34.

Raffestin, C. (1986). Elements for a Theory of Frontier. Diogenes, 34, (1).

Raffestin, C. (2007). A propósit d'algunes paradoxes limitológiques. Documents d'Anàlisi Geogràfica, 50 (200), 121-133.

Reoratti, C. (1982). Migraciones y frontera agraria: Argentina y Brasil en la Cuenca del Alto Paraná. En J. Balán (Comp.). Poblaciones en movimiento. Paris: UNESCO.

Ritter, K. (1862). Geographical Studies. Boston: Goul and Lincoln.

Sáenz, M. (1977). Notas para una historia del pensamiento geográfico, geografía sistemática y geográfica radical. Cuadernos Geográficos de la Universidad de Granada, 7, 353-360.

Said, E. (1978). Orientalismo. Barcelona: Anagrama.

Sandoval, E. (2008). Memoria y conformación histórica de un espacio social para el consumo entre el noreste de México y el sur de Texas. Relaciones, XXIX (114), 235-273.

Santis, H. (2002). Perspectivas de la geografía. Revista de Geografia, Norte Grande, 29.

Santos, M. (1978). Per uma Geografia nova. Sao Paulo: Hucitec-Edusp.

Santos, M. (2005). O retorno do território. Debates. Territorio y movimientos sociales, VI (16), 251-261.

Santos, M. (2006). O dinheiro e o territorio. En M. Santos et al. Territorio, territorios- ensayo sobre o ordenamiento territorial. (2a. ed.) Rio de Janeiro: DP\&A. p. 13-21.

Semple, E. C. (1911). Influences of geographic environment, on the basis of Ratzel's system of Anthropo-Geography. New York: Holt.

Sidaway, J. D. (2005). The Geography of Political Geography. Working Paper. Singapore: Deparment of Geography, National University of Singapore. 
Sluyter, A. (2001). Colonialism and landscape in the Americas: Material/Conceptual Transformations. Annals of the Association of American Geographers, 91 (2).

Thoening, J. C. (2006). Territorial Institutions. En R.A.W. Rhoades, S. A. Binder \& B. A. Rockman. The Oxford Handbook of Political Institutions. Oxford: Oxford University Press.

Tunander, O. (2001). Swedish-German geopolitics for a new century. Rudolf Kjellén’s "The State as a Living Organism”. Review of international Studies, 27, 451-463.

Vallaux, C. (1914). El Suelo y el Estado. Madrid: Daniel Jorro.

Vicens Vives, J. (1961). Tratado general de geopolítica. Barcelona: Vicens Vives.

Vitar, M. B. (1997). Guerra y misiones en la frontera Chaqueña del Tucumán. Madrid: CSIC, Biblioteca Historia de América.

Viqueira, J. P. (1994). Regiones naturales, regiones nominales y regiones vividas. Ponencia presentada en el VI Simposio de Historia y Antropología Regionales, organizada por la Universidad Autónoma de Baja California Sur.

Whittlesey, D. (1943). Haushofer: the geopoliticians. En E. M. Earle (ed.). Makers of modern strategy. Military thought from Machiavelli to Hitler. Princeton: Princeton University Press.

Wiegert, H. W. (1956). Geopolítica. Generales y geógrafos. Buenos Aires: Huella.

Zunino, H. M. (2000). La teoría de la estructuración y los estudios urbanos. ¿Una aproximación innovadora para estudiar la transformación de las ciudades? Scripta Nova. Revista Electrónica de Geografia y Ciencias Sociales, 69 (74). Recuperado de http://www.ub.es/ geocrit/sn-69-74.htm.

Zusman, P. B. (2000). Tierras para el rey. Tres fronteras y la construcción colonial del territorio del Río de la Plata (1750-1790). Tesis doctoral. Bellaterra: Universitat Autónoma de Barcelona.

Zusman, P. B. (2002). Geografías disidentes. Caminos y controversias. Documents d'Análisi Geográfica, 23-44.

Zusman, P. B. (2006). Geografías históricas y fronteras. En D. Hiernaux \& A. Lindón. Tratado de Geografía Humana. México: UAM, Anthropos.

Recepción: 20 de noviembre de 2011

Evaluación: 24 de enero de 2012

Aprobación: 14 de junio de 2012 